\title{
Binge drinking: all too prevalent and hazardous
}

\author{
Ken Flegel MDCM MSc, Noni MacDonald MD MSc, Paul C. Hébert MD MHSc
}

A lcohol use is the third greatest contributor to the global burden of disease, ${ }^{1}$ estimated to cause $3.8 \%$ of all deaths. Among people aged 15 to 44 years, alcohol is estimated to result in $4.6 \%$ of all disability-adjusted life years lost and a disproportionate number of fatal injuries. ${ }^{2}$

Heavy drinking is classified as the consumption of more than $210 \mathrm{~g}$ of alcohol per week for men and more than $140 \mathrm{~g}$ per week for women, owing to differences in clearance and body size. As a metabolic poison, heavy alcohol use is associated with cardiovascular disease, oral cancers and liver cirrhosis. As an intoxicant, it causes dependency, injuries and trauma as well as substantial social harms. ${ }^{3}$

Binge drinking is a particularly dangerous form of alcohol consumption. Men who consume five drinks (50 g) or more or women who consume four drinks (40 g) or more in one sitting are binge drinkers. Binge drinking is reported to be twice as likely as daily heavy drinking to cause acute myocardial infarction or death. ${ }^{4}$ It is also associated with unwanted or unsafe sex, violence and injuries of all types.

Over the past five years, $8.8 \%$ of Canadians reported binge drinking; most were men aged 15 to $24 .^{5}$ Among high school students in the US, where the legal drinking age is 21 , just over $40 \%$ consume alcohol, and approximately two-thirds of them admit to binge drinking. ${ }^{6}$ These high rates have been attributed to the decreasing cost of the cheapest forms of alcohol, ${ }^{7}$ increasing availability and advertising.

A growing body of evidence points to adverse health effects associated with binge drinking, but too little is known about how to reduce this behaviour. For instance, will increasing the cost of alcohol or decreasing access by constraining the time and place where alcohol is sold reduce binge drinking among young people? ${ }^{1}$ One of the few studies on the effects of increasing the minimum unit price per alcoholic drink indicated that such a policy might decrease rates of binge drinking. ${ }^{2}$

Does the discounted sale of alcohol for short periods, such as during "happy hour," do anything more than promote risky behaviour? It seems obvious that happy hour promotes heavy alcohol use in price-sensitive people such as college students and the socially disadvantaged. It also propagates the message that binge drinking is socially acceptable.

No one wants to live in a "nanny state." However, as taxpayers, we are already feeling the burden of heavy alcohol use. Simple evidenceinformed regulations and policies are worth considering.

Given the many stakeholders involved in the sale and consumption of alcohol, we need a national strategy for controlling overall alcohol use. Public health agencies, the hospitality industry, liquor manufacturers and control boards, municipalities and major granting agencies should collectively turn their attention to evaluate strategies to curb binge drinking. Populationbased interventions for study might include minimum unit pricing, restricting availability or advertising. At the individual level, counselling by health professionals about early problem drinking might be a good study candidate.

As we await evidence about beneficial interventions, we should strengthen surveillance programs so we can increase public awareness of the high prevalence and known dangers of heavy and binge drinking. Health professionals should routinely enquire about alcohol consumption, alcohol-related risk behaviours and binge drinking, especially among young people. Children and youth should be remind-ed that binge drinking can result in serious loss of self-control and therefore heighten the risks of involvement in dangerous sex, rape, violence or injuries. Most important, good role modelling by parents is the best way to teach responsible alcohol use.

\section{References}

1. Alcohol and Public Policy Group. Alcohol: no ordinary commodity — a summary of the second edition. Addiction 2010;105:769-79.

2. Anderson P, Chisholm D, Fuhr DC. Alcohol and global health 2. Effectiveness and cost-effectiveness of policies and programmes to reduce the harm caused by alcohol. Lancet 2009;373:2234-46.

3. Giesbrecht N, Stockwell T, Kendall P, et al. Alcohol in Canada: reducing the toll through focused interventions and public health policies. CMAJ 2011:183:450-55.

4. Ruidavets J-B, Ducimetière P, Evans A, et al. Patterns of alcohol consumption and ischaemic heart disease in culturally divergent countries: the Prospective Epidemiological Study of Myocardial Infarction (PRIME). BMJ 2010;341:c6077 doi:10.1136/bmj.c6077.

5. Canada Health and Drug Use Monitoring Survey. Ottawa (ON): Health Canada. Available: www.hc-sc.gc.ca/hc-ps/drugs-drogues /stat/2009/tables-tableaux-eng.php\#t6. (accessed 2011 Jan. 6).

6. Vital signs: Binge drinking among high school students and adults - United States, 2009. MMWR Morb Mortal Wkly Rep 2010;59:1274-9.

7. Burki T. Changing drinking patterns: a sobering thought. Lancet 2010;376:153-4.
Competing interests: See www.cmaj.ca/misc/cmaj _staff.dtl

\section{Affiliations: Senior}

Associate Editor (Flegel), Section Editor, Public Health (MacDonald), Editorin-Chief (Hébert), CMAJ With editorial advisory team member Matthew B.

Stanbrook MD PhD

Correspondence to: $C M A J$ Editor,pubs@cmaj.ca

CMAJ 2011. DOI:10.1503 /cmaj.110029 